This item was submitted to Loughborough's Research Repository by the author.

Items in Figshare are protected by copyright, with all rights reserved, unless otherwise indicated.

\title{
Doing calories: the practices of dieting using calorie counting app MyFitnessPal
}

\section{PLEASE CITE THE PUBLISHED VERSION}

https://books.emeraldinsight.com/page/detail/Metric-Culture/?K=9781787432901

\section{PUBLISHER}

(C) Emerald Publishing Limited

\section{VERSION}

AM (Accepted Manuscript)

\section{PUBLISHER STATEMENT}

This work is made available according to the conditions of the Creative Commons Attribution-NonCommercialNoDerivatives 4.0 International (CC BY-NC-ND 4.0) licence. Full details of this licence are available at: https://creativecommons.org/licenses/by-nc-nd/4.0/

\section{LICENCE}

CC BY-NC-ND 4.0

\section{REPOSITORY RECORD}

Didziokaite, Gabija, Paula Saukko, and Christian Greiffenhagen. 2019. "Doing Calories: The Practices of Dieting Using Calorie Counting App Myfitnesspal”. figshare. https://hdl.handle.net/2134/32592. 
Doing calories: The practices of dieting using calorie counting app MyFitnessPal

\title{
Gabija Didžiokaitè
}

Gabija Didžiokaitè (MSc (Research) in Social Sciences, specialising in Medical Anthropology, from the University of Amsterdam) is a $\mathrm{PhD}$ candidate at Loughborough University Social Sciences Department. Her current work looks at practices of self-tracking, more specifically at the use of calorie counting and diet tracking app MyFitnessPal.

Paula Saukko

Paula Saukko (PhD, University of Illinois at Urbana-Champaign, USA) is a Reader in Social Science and Medicine at the Department of Social Sciences, Loughborough University, UK. Her work is located between Medical Sociology, Science and Technology Studies and Communication and focuses on new medical/diagnostic technologies, digital media and qualitative methodology. She is the author of The Anorexic Self: A Personal and Political Analysis of a Diagnostic Discourse (SUNY Press, 2008) and three other books and numerous articles in journals, such as Social Science \& Medicine and Sociology of Health and Illness.

Christian Greiffenhagen

Christian Greiffenhagen (DPhil, University of Oxford) is Assistant Professor in Sociology at the Department of Sociology at The Chinese University of Hong Kong (CUHK) and Senior Lecturer at Loughborough University. He works in the areas of Science \& Technology Studies (STS) and Human-Computer Interaction (HCI), where he uses ethnomethodology and conversation analysis to study scientific work and new technologies 'in use'.

Address correspondence to the first author at the Department of Social Sciences, Brockington Building, Loughborough University, Loughborough LE113TU or g.didziokaite@1boro.ac.uk

\begin{abstract}
The existing literature on fatness has critically discussed meanings and morals associated with body weight and explored people's experiences of weight loss attempts. However, little attention has been paid to the practices of dieting - how it is 'done'. Based on an interview study involving 31 participants, who shared their self-tracking experience of using the MyFitnessPal calorie counting app, we focus on the practices of 'doing' calories. First, we discuss the practices of temporality of logging food, showing that the use of MyFitnessPal not only has to be fitted into daily routines but can also transform them. Then, we look at the practices of precision or users' various ways of turning the 'messiness' of food into precise numbers. Lastly, we explore users' practices of adjustments - their attitudes to adherence to their daily calorie goal and ways of dealing with going above it. Based on our findings we suggest calorie counting is not a straightforward data collection, but one that involves constant practical strategies and negotiations, and can both influence and be influenced by other everyday practices.
\end{abstract}

\section{Keywords}

Self-tracking; dieting; calorie counting; quantified self 


\subsection{Introduction}

Fat, perceptions of it and ways of tackling it are popular topics addressed by diverse disciplines. Historical studies have outlined how corpulence became a social problem from the 19th century onwards (Schwartz, 1986). Today this vilification continues with 'war on obesity' fought by governments and medical professionals (Gard \& Wright, 2005). Researchers have discussed the different moral evaluations associated with fatness and thinness, such as body/mind, lack of control/self-control and gluttony and greed/restraint (Bordo, 1993; Gilman, 2010). Likewise, it has been shown that eating and food have for a long time been morally evaluated (Coveney, 2006). Researchers have looked at the representation of fat people in the media and shown that the portrayals are mainly negative (Contois, 2013). Consequently, with all the negativity attached to 'excessive' eating and fatness, pressures to control eating habits and get thinner coming from governments and media, many resort to dieting and other means of weight loss. Studies have explored the experiences of such endeavours by exploring diet groups such as Weight Watchers (Heyes, 2006; Stinson, 2001), online dieting (Niva, 2015) and surgical weight management (Throsby, 2008).

We thus have some knowledge about attitudes towards fatness, the role of the media in changing and sustaining these attitudes, and the feelings and opinions of those engaged in dieting. In short, researchers have focused on what people think, feel, and know about body weight, calories and dieting. However, despite the interest in fatness and pursuits of weight loss, the practices of dieting, what people $d o$ when they wish to lose fat and otherwise manage their weight have been little explored. Guided by the practice-oriented traditions of science and technology studies (STS), in this chapter we aim to fill this gap by exploring the 'doings' of calorie counting.

Researchers working in STS have highlighted the importance of observing the everyday practices of scientists as well as users of technology. This is essential for noting the efforts required to establish a fact, in the case of scientists, or to adopt a technology. This 'invisible work [...] outside formal work relations' (Oudshoorn, 2008, p. 275) is, thus, the focus of this chapter. We explore what using MyFitnessPal requires its users to do to count the calories they consume. We explore the practical temporality, precision and cheating that constitute calorie counting with MyFitnessPal. We show that each of these aspects requires efforts from MyFitnessPal users if they wish to establish a correct calorie count, and these efforts, in turn, affect users' eating habits. However, despite the constraints imposed by calorie counting, users are negotiating their use and adopting MyFitnessPal to suit their lives.

\subsection{Exploring practices of eating and dieting}

While perceptions and experiences of eating and dieting attracted significant attention, the same cannot be said about their practices. Comber, Hoohout, Van Halteren, Moynihan and Olivier (2013) investigated food practices, exploring how the practices of buying, preparing and eating food are managed. These practices are affected by time (time available to shop, cook, eat, and the time available food stays fresh) and people (children and guests influence what food the family eats). Comber et al. (2013) showed that people do not have precise meal plans and follow routines for both buying and preparing food. Eating out was providing freedom to think more about taste than the healthiness of the food. Similarly, Kerr, Tan and Chua (2014) researched practices of food preparation to understand cooking needs. They too found that people do not plan meals much and usually buy similar foods. People usually weigh 
ingredients only when they bake. While food is usually cooked alone, social elements such as advice, sharing and feedback influence the process.

Food practices related to dieting have been explored by De la Rocha $(1985,1986)$, who has looked at everyday food measuring and counting practices evoked and guided by participation in Weight Watchers weight loss group. She interviewed and observed measuring practices of ten females participating in the Weight Watchers programme. At the time, Weight Watchers required dieters to consume a certain number of portions of different foods during a week. All foods were allowed if the amount that was eaten followed the recommendation. Hence, weightwatchers needed to engage in a lot of measuring. De la Rocha notes that based on their approach to dieting, there were two groups of dieters - the meticulous controllers of food intake and others who relied on previous dieting experiences and tried to eat very little and used the Weight Watchers programme only as a rough guide.

De la Rocha's (1986) focus was not so primarily on dieting, but on 'everyday arithmetic'. Thus, she focused on participants' practical ways of measuring food without employing scales or measuring cups. For example, they would measure the amount of food that is considered as a portion by Weight Watchers once and, for example, note a decorative marking on the dish to which the food is filled, so that next time they could use this as a reference for the required quantity.

\subsection{Understanding practices of dieting through STS perspective}

To unpack and understand the practices and implications of everyday usage of weight loss technology, we adopt an STS perspective of technology and quantification. STS researchers argue that numbers used by various tools are not stable, already-existing entities, but rather are produced through commensuration and measurement, which change 'qualities into quantities', and this change 'creates new things and new relations among things' (Espeland \& Stevens, 2008, p. 412). Martin and Lynch (2009), for example, show that counting chromosomes and people is not a matter of simply ascribing a number to quantity but rather involves negotiations of practicalities to, first of all, make those things countable. Following this, we wanted to explore and highlight how people used MyFitnessPal as a dieting technology, and how they made the food and calories countable in their daily practices of food planning, preparation and eating.

In what follows we present the results of the exploration of practices of dieting from a STS perspective. We show that, even though calorie counting is ostensibly 'automated' in that users do not count i.e. add and subtract the numbers of calories, they still need to put a lot of effort to transform the foods they eat into numbers of calories. Moreover, calorie counting, as a practice directly linked to food, is infused with moral undertones, which can influence what is counted and how.

\subsection{Methods}

We conducted 31 interviews with users of MyFitnessPal; the participants fell into three basic groups. The participants include 12 men and 19 women, and their age ranged from 22 to 53 years. Most participants were based in the UK, East Midlands area. Ethical clearance was obtained from the authors' university before commencing recruitment and interviewing. To ensure anonymity, we use pseudonyms when quoting participants.

Our recruitment was informed by a desire to include everyday self-trackers - people who started tracking on their own and were not part of any self-tracking community - and, hence, to avoid studying members of the Quantified Self community, which has been researched a lot. 
Thus, we approached personal trainers in the East Midlands area, some of whom referred us to their clients, who used MyFitnessPal. We also posted recruitment ads on a participant recruitment website callforparticipants.com, on local sports Facebook groups and on the bulletin board for local university staff and students. The sole criterion for participation was a previous or present use of MyFitnessPal.

The interviews were semi-structured and consisted of questions about the history of MyFitnessPal use, usual use practices, and evaluation of the app. The interviews were conducted by the first author mostly $(n=28)$ face to face, with few $(n=3)$ done through Skype video calls. The interviewer recorded and transcribed all the interviews, and conducted a thematic analysis.

\subsection{How calorie counting is done}

\subsubsection{PRACTICAL TEMPORALITY}

One of the first things one must decide when using MyFitnessPal is when to log the food eaten. There is no prescribed time of doing it, and thus users can decide whether they log before, during or after eating. These choices have their different advantages and disadvantages that are connected to individual routines and aim for precision of the food log. However, decision, when to log, can also influence the eating habits. Logging during meals disturbs eating habits as cooking or eating are being interrupted to enter all the foods into MyFitnessPal. Logging in advance highlights the reactivity of calorie counting as measurement (Espeland \& Sauder, 2007) - instead of counting the calories they consume, participants are planning their meals and adjusting them according to the calories suggested by the app. It not only changes the calorie counting as a measurement but also affects participants' eating behaviours requiring them to be regulated in advance.

Logging food for calorie counting could be quite time-consuming and needed to fit in sometimes very busy schedules. So most often participants would log food during their breaks at work or at the end of the day, after work and dinner, when they had more free time to sit down, remember and log all the things eaten:

Eve: I mean I had my breakfast at home, and then I get to work I put in while I'm having a coffee, before the morning meeting, then after lunch, I put it in, then after dinner, I put it in.

Lilian: It can be time-costly [...] I tend to do when [...] my son's gone to bed because you can just sit there and work it all out, but you do have to have the patience.

Some participants knew that logging 'long after' a meal may be problematic and were explicit about avoiding logging foods only at the end of the day because it made it easy to forget what was eaten:

Samantha: I think if I remember I'd put it in after I've eaten the food, I think if you tried to at the end of the day you'd forget half the things you've eaten. I used to do food diary when I was training as a swimmer, so I was aware that if you did it at the end, you forget everything. [our emphasis] 
Samantha echoes the nutrition scientists who use food diaries and note that participants forgetting and therefore not logging eaten foods is a frequent issue (e.g. Macdiarmid \& Blundell, 1998). This concern was mentioned by some other participants as they underlined the importance of timing for the 'reliability' of their records.

In addition to issues of remembering, counting calories at the end of the day or long after the food was eaten was posing a risk of going above the calorie norm, because you would lose the possibility of reflecting on what you are eating prior or during consumption:

Alex: I would tend to be putting in food kind of afterwards. So, you'd have Subway, when I've been out, I'd grab a subway or something, out in town, and then an hour later you come to put it in and see that that was about 800 calories - bloody hell, didn't know that.

So, not logging before a meal could lead to an unpleasant surprise and possibly going over the calorie limit. Yet as the earlier quotes show, many participants were logging long after eating despite the potential of 'unreliable' data. This indicates that in many instances convenient use of MyFitnessPal that fits with one's own life is more important than 'perfect' use that generates 'reliable' insights. This indicates that often convenient use that fits with owns life is more important than 'perfect' use that generates 'reliable' insights.

Some participants addressed the problem of 'reliability' by logging while eating or cooking as they could weigh and search for the ingredients or meals straight away, so there was less chance of forgetting:

Julie: Usually [...] I put my breakfast in as I'm eating my lunch [laughs]. But then tea, I would put it while everything is cooking, I know I've got it ready and it's fresh in my mind, if I do forget.

Gemma: I'd probably enter it while I was cooking and then mend it, say if I haven't eaten it all, I'd mend it afterwards, but I would put it in while I was cooking so that I knew exactly what was in there.

Logging while cooking helped to remember all the ingredients and made it possible to scan the barcodes of packets, making the log more accurate and precise. Logging inevitably interrupted the eating or cooking and made participants focus on the calorie values of food.

Others were even more determined to get the numbers right and to be in control and therefore counted calories before eating, often logging in the morning all the items they were going to eat during the day:

Georgina: And then either I see what calories I've got left for dinner, or I know what I'm having, and I put that as well. So, I do it, I do it as much as I can first thing, so kind of like you know what you can have the rest of the day. [our emphasis]

In addition to safeguarding from going above their calorie limit, logging in advance enabled participants to determine if any other food in addition to the planned meals could be consumed. And for sports enthusiasts, like Barney, logging in advance also helped to ensure that all the required nutrients will be consumed:

Barney: Sometimes I know what I'm going to eat for the day, and I might just put it all in at once [...] for example, yesterday evening I was going to have sweet potato with steak, I put in the steak, I put in the sweet potatoes. I will look on MyFitnessPal - oh, that's, if I was like I said [...] I want a hundred grams 
[of] sweet potato, I realise that's not really enough, so I can use it to add, use MyFitnessPal to sort of help me prepare my meal. [our emphasis]

Georgina's and Barney's quotes point to the reactivity (Espeland \& Sauder, 2007) of calorie counting. Participants were not just making a record of their food as they ate but aimed to regulate their eating by planning and counting calories in advance. Hence, counting calories with MyFitnessPal as other kinds of self-tracking has a prospective character (Rooksby, Rost, Morrison \& Chalmers, 2014).

The quotes also confirm the STS argument that measuring is never neutral or passive, but rather performative since it can 'cause people to think and act differently' (Espeland \& Stevens, 2008, p. 412). Participants were not just tracking their calories but regulating their eating according to them. Moreover, the need to measure - $\log$ calories - sometimes was interrupting the eating. Hence, the timing of logging affected their eating habits. Exploring the timing of calorie logging not only reveals the practical considerations that need to be taken when deciding when to $\log$ but also shows different ways that calorie counting influences eating practices.

\subsubsection{PRACTICAL PRECISION}

Measuring food intake is not straightforward. Apples, for example, come in different types and sizes, and to get a correct calorie count for the eaten apple one needs to find the exact type, its size or if being more precise, its weight. This gets even more complicated when eating meals that have many different ingredients. Hence, food and calories have to be constituted (Potter, Wetherell, \& Chitty, 1991) as countable through practical negotiations. The participants of the present study were not scientists wanting to know exactly how many calories every item they ate had. They usually wanted to know 'roughly' how much they were eating and therefore adopted appropriate attitudes to their calorie counting. As Gemma put it: 'I mean you're never going to get this exact calorie, I don't think. But as long as you've got an educated guess as to what you're eating, I think it works very well.' Participants' stories reveal different ways they achieved the desired precision, which indicate that attitudes to the precision range on a continuum from approximations to very precise counting. Hence, the calorie count - a number that appears to be exact and objective - is approximate and arrived at in messy and individual ways. Moreover, whether measured by grams or approximated by handfuls, food becomes estimated in a more constricting manner, requiring attention to the quantities that might not have been given before.

Some of the participants did not measure but rather guessed, the weight of their food items. Some, like Vijay, did not have kitchen scales. Others, simply thought that weighing food in addition to logging it would have been too bothersome and, like Joe, they could not do the food logging if it had required that much effort:

Joe: I wouldn't [weigh Ready Brek out], no I don't go to that length. A Hundred millilitres is very very little. I wouldn't go to the extent of actually weighing or measuring it out. Cause I think if I did that I don't think I would be able to maintain.

These participants argued that not measuring resulted only in small inaccuracies (especially of less calorific foods), and did not affect the overall calorie count much. Therefore, it is not essential to measure precisely.

Some participants who were reluctant to measure food argued that the imprecisions would average out over time: 
Stacey: I just put in twenty [grapes], I could weigh them up, but I never do that, just make my lunch and just eat twenty. I sort of go on, some days, some weeks they'll be really big, and I probably wouldn't be putting enough in, but other weeks they probably be a lot smaller, so I guess over the year I average out.

Here we can see that participants were not so much interested in keeping a precise 'daily record', but more in having an aggregate log.

Some participants, similarly to those in the De la Rocha (1986) study, found practical ways of gaining at least some precision without overburdening themselves with constant measuring. One method was measuring the foods they used to eat often once - and then using that as a template for the future.

Gemma: So, I'd always, if it's something new I'd always measure it first, first time I used it, and then afterwards just try and remember what it was that I had last time.

Anamaria: Because we bought a really small kitchen scale, I weigh, I used it once to weigh like a pear once, to weigh an apple once and I'm just using that.

Those who used the app more frequently or were familiar with calorie counting often learned to estimate weight from the size or volume:

Georgina: And I know these measurements, I used to put my bowl on a set of scales and zero it and measure, and now I know I have a scoop, how many spoonfuls that makes, and the blueberries is well under 100 grams.

These techniques were helpful, as most participants said they routinely ate the same food items. By using such methods, participants established a middle ground, as they avoided both just guessing the weight of their food or/and constantly measuring it, and instead created ways of approximation.

To help with precision, MyFitnessPal has a scanner so that users can scan the barcodes of packed foods straight into the app, which reads their calorie content. However, often the food that participants ate neither had a barcode nor could be found on the database. Hence, participants encountered a special difficulty of recording eating (and being precise) if they could not find items in the database. In those cases, they might have to 'guess' what would be a similar item:

Lilian: And half the time it's there but if it isn't there I would just look for the best fit, so even if it's not a complete precise, there's an estimate, I choose the most, the nearest thing, you know what I mean.

Roy: So, if I'd been out, I don't know, if I'd been to Franky and Benny's or something, where there was a Harvester equivalent, and you kind of think - 'well I've been to both of those places, they're roughly about the same amount'. I would pick the one that's in MyFitnessPal, rather than just try and build something.

With complex items, i.e., those that consisted of several ingredients, this would involve more complex 'guesswork':

Q: So, but then I imagine, if you put like a roast dinner plate, it probably has something like from 400 to 1000 calories. So how did you choose between? 
Georgina: Well I knew I had cauliflower cheese, I knew how many roast potatoes I had, and whether they were cooked in fat. Cause I've been observing for so long, I suppose I had an idea. I knew that plate of dinner wasn't 400 [...] I know there's a temptation to put in 400 and think oh, I've got another 800 to go, but I err on the side of going too much, rather than too few calories.

Hence, in calorie counting as in other counting practices, to count at least approximately right, the user needs to know what they are counting, and be aware which numbers are wrong (Martin \& Lynch, 2009). These quotes show that measuring calories for a long time enabled participants to estimate them based on prior experience. Thus, calories become integrated into their eating practices - they can 'guess' calories based on prior experience.

Despite recognising that calorie counting as measuring could not be very precise, a few participants wanted at least to do their part 'correct' - they aimed to be precise and weighed everything they were eating. For many, this was done to get the 'correct' portion as defined by the app or food package. Alex explained how the meaning of the 'correct' amount of food changed when he was dieting:

Well because, maybe because I was using it on sort of weight loss aim, was always kind of choosing to go for sort of portion size that it says on the packet, rather than just pouring until you reckon that's about right. So yeah it would be sort of 50 gram, whatever would be just poured out, I could probably because it was 50 gram, it's not because it's the amount that I wanted or anything like that, or because it was the amount that I need to, to the target, sort of, if I was able to sort of meet the target by going to 35 grams or something.

When Alex was tracking his diet, the portion size was regulated by the weight loss aim, rather than by a whim, as it was when he was not tracking. Hence, because he was aiming to lose weight, he needed to eat the 'right' portion and, therefore, measure the 'correct' amount. Similarly, Barney explained that it was easy to get the weight and portion wrong by just estimating:

And like if I was weighing out fruit or something, you don't quite get an appreciation like, 80 grams you can actually get it quite wrong, you don't realise how wrong you can get it, so [weighing] is useful.

So, measuring was presented as a way to get the 'right' amount and as an opposition to illinformed guessing, where it was easy to not 'realise how wrong you can get it' and damage your weight loss. Hence, precise logging of food with MyFitnessPal affected what participants perceived as a portion, and consequently their eating practices.

Power (2004, p. 769) argues that we expect measurement to 'not to depend on who is doing it' and therefore be replicable. However, as the discussed examples show such expectations are hard to meet when it comes to calorie counting. Different users approach measurement differently, depending on their commitment to precision and control of their diet. There seemed to be no unified way of how food logging for calorie counting should be done. The stories signal the messiness of the ways the precision was being achieved and the subjective side of the calorie values.

\subsubsection{PRACTICAL ADJUSTMENTS}

Participants often had a routine diet that they established as fitting under their calorie limit. However, as for dieters in Niva's (2015) study, events, such as socialising, would make 
participants deviate from the routine and eat more calorific meals. These were referred to by some as 'cheat' or 'treat' meals, highlighting that food consumption was fraught with complex social evaluations associated with doing the wrong thing or rewarding oneself (Coveney, 2006; Lupton, 1996). Calorie counting added another dimension to these evaluations as participants not only morally evaluated these actions but also had to deal with the 'excess' consumption practically. While some participants aimed to minimise the influence of 'excess' consumption to the calorie limit by eating less beforehand, others would stop counting calories altogether if they anticipated the 'excess'. MyFitnessPal was not a tool to keep a perfect record of calorie consumption, but rather an aide to help lose weight. Thus, manipulation of the app's use indicates that despite the rigidness MyFitnessPal required, its use had to fit the users' lives, and sometimes that meant 'cheating'.

Some participants, especially the sports enthusiasts, would actively avoid going over the calorie limit. If they wanted to abandon the planned diet and eat something more calorific, they would try to build a calorie deficit either eating less during the week before or on the day. To do this, they would need to engage in the earlier mentioned planning of meals, so that they could compensate their 'cheat' or 'treat' meal by being more austere in advance. This kind of 'allowance', especially the weekly one, is not in any way encouraged or supported by the app, so participants came up with this idea themselves and needed to keep these 'saved' calories in mind. For example, Freddie, who was engaged in body building and aimed to get leaner before his annual photo shoot, would calculate the calorie and nutrient allowance he needs to 'save up' in advance and which meals to cut those calories out before going out:

[...] that meals gonna be a thousand calories, those 1000 calories need to come out of somewhere, ok how can you use 200 calories out of my evening meal, or 400 calories, so that's 600 calories I need to find elsewhere in the week, to make sure I hit under.

Similar strategies were used by participants, who only wanted to lose weight. They might not be as elaborate as Freddie, but would simply try to eat less before going out for a meal:

Lilian: Something that was gonna take my calories, say in the evening meal, went out to the pub for dinner, then I make sure that in the mornings I was eating, I don't know a little bit of fruit for breakfast or you know, yoghurt, or you know, something smaller.

This confirms the argument made earlier that calorie tracking is prospective, as people anticipated 'excess' calories. Participants often talked about these negotiations, reflections and preparations in moral undertones, describing the eating out occasions as 'naughty', which highlights the way in which the moral understandings of consuming excess food and the use of the app supported each other:

Q: But then, as you mentioned now, so if you go for a meal or have a birthday or something like that, do you try then to cut out calories before, you know, by exercising or by eating less?

Eve: Yes, I would do. I would probably eat less, I would sort of try and make sensible choices.

Q: So, like an allowance for you to...

Eve: Be a bit naughty. Yeah.

Similarly, the participants referred to the austere regimes adhered to prior to eating out or more, as being 'good': 
Stephen: If I knew that meal was coming up, I would try and be good that week, I try and be good the week afterwards, be better than I would normally [...] I wasn't too hard on myself. I can see how people could be hard on their selves on this, it could make people paranoid, erm, and I felt like I was probably getting a bit that way towards the end.

Coveney (2006) argues that nutrition provides an ethical framework through which to construct ourselves as certain kind of persons. Hence, there seemed to be a moral difference between strict and regulated diet ('be good') and the occasional meal out ('be a bit naughty'). This echoes the religious language used by the weight loss industry (Contois, 2015) and commercial weight loss groups (Bacon, 2015), with 'good' and 'bad' foods constituting sin or salvation. However, Stephen recognised that it is easy to get 'paranoid' while logging food, suggesting that too much strictness was not welcomed. This goes hand in hand with Crawford's (1984) findings that people find both control and release essential for health.

Another way of dealing with 'excess' is by stopping calorie tracking altogether. For example, Ruth would stop logging if a breach of calorie limit could be anticipated:

No. Erm. When I first started, when I was kind of enthusiastic about it, and I was trying to lose weight for a holiday for the summer, and I then was quite good about making sure that I'm putting everything in every day. But even then, still at the weekends if I had more than one glass of wine, I was like - there's no point of putting it in, cause I'll just be well over. Erm. I always log my exercise cause that makes me feel better, but I don't always log, if I know that I had a day where I went over, sometimes I just won't put it in.

This illustrates the way in which excess calories are manipulated out of existence by not logging them in. Ruth tells that initially she was 'good' and logged everything, but over time she learned to be more selective in accordance to what makes her feel 'better'. Georgina too omitted weekends when the consumed wine will tip over the calorie limit:

Georgina: ... it's a day like a Saturday, and I'm out, and I'm drinking lots of glasses of wine, I won't even bother that day, I just think I can't even think about [logging food on MyFitnessPal]. And I know it's about 4000 calories today, so. I don't bother putting that in because it doesn't, I can't see any gains in putting that in. I know I've gone over [the calorie limit], MyFitnessPal doesn't do anything to make me think - 'I might as well fill in 4000 calories today'. It's when I know I'm gonna stick under it, I fill it in properly, if I know I've gone over it, and the food's too difficult to log, I just don't bother, because it's too much hassle for what.

Like Ruth, Georgina finds some calories - like the calories of wine - not worth the effort of logging as the knowledge that calorie limit has been breached when she is socialising is not helpful in her weight loss attempt.

Measurements are reactive, as they intervene and often discipline the world they depict (Espeland \& Stevens, 2008). Ruth's and Georgina's examples indicate that sometimes participants did not find the 'reactivity' of all calorie counts useful, and therefore sometimes chose which numbers to 'make'. Only the 'successful' days below the limit were logged as they made participants feel good about themselves and helped them be motivated and continue with calorie counting. In contrast, there was no use in seeing the numbers of 'unsuccessful' days when calorie limit was breached, and which would only reflect 'failure'. 
The stories of participants might not exactly indicate the 'soft resistance' (Nafus \& Sherman, 2014) found among other self-tracking activities. Yet, they reveal defiance of the scenarios of use embedded in the app (i.e. log everything that you eat) as users negotiated control and release (Crawford, 1984) for calorie counting that would be useful and comfortable to them.

\subsection{Discussion and Conclusion}

Current literature on weight loss practices does not focus much on the practices of dieting, or how they influence daily lives or practices rather than the body or self-image. We explored the practices of dieting by calorie counting, and the findings emphasise three points. Firstly, calorie counting, even if somewhat automated with such apps as MyFitnessPal, is not effortless, nor done without some planning. Earlier research on online dieting (Niva, 2015), commercial weight loss groups (Stinson, 2001) and surgical weight loss (Groven, Råheim, \& Engelsrud, 2015) has shown these activities as also requiring considerable effort. The present study supplements this common finding by 'unboxing' the efforts. Instead of investigating the attitudes and/or feelings towards calorie counting, we have explored the 'doing' of calorie counting. Calorie counting, as any other practice of counting, involves 'procedures for assigning numbers to objects' (Martin \& Lynch, 2009, p. 261), and people using technologies such as MyFitnessPal have to put a lot of effort to 'make' the numbers of calories. It requires finding the time, tools like scales, and knowledge, not to mention skills, to employ all these correctly.

Therefore, secondly, the present exploration of practical aspects of calorie counting shows that there is no unified way to count calories and, thus, the objective number of a calorie count was achieved in messy ways. Each user responded differently to the practical and 'ethical' considerations, and negotiations involved in calorie counting. De la Rocha (1986) divided her participants into two groups based on their way of dieting. However, we found that the participants of the present study could not be classified that categorically. They ranged on a continuum between relaxed and very precise counting, with some switching places depending on the practices (e.g. would log food in advance, but would not measure). As they were not looking to build a precise record of their calorie consumption, participants did calorie counting in the way that best fitted their goals, lifestyle (sports enthusiasts needing more precision or people wanting to lose weight needing approximation) and practical arrangements.

This leads to the third point. Earlier research has noted that dieting (Bordo, 1993; Heyes, 2006) or weight loss surgeries (Throsby, 2008) can affect not only the body but also the experience of self. We want to extend this argument, as a close look at the practices of calorie counting lets us see how calorie counting both influences routines of people doing it and is influenced by them. Needing to log food eaten affects eating practices. Compared to usual food practices, food practices when dieting are more regulated as food needs to be standardised, classified and counted.

People rarely measure foods and ingredients (Kerr, Tan, \& Chuba, 2014). However, dieters needed to know how much they are eating and, therefore, measure food before eating, which sometimes affected the meaning of portions. Many related to food through its calories as often they dictated in advance what could be 'safely' eaten to fit in the daily goal or indicated that less food needs to be eaten in the morning to be able to enjoy a dinner in the restaurant.

Nonetheless, calorie counting with MyFitnessPal needs to be appropriated by the user so that it becomes feasible and blends into daily life. The participants knew that the best time to log food was when it was eaten, but they often logged whenever it suited them best. They knew that to be precise they need to measure food, but this often was seen as too burdensome or 
unnecessary, and participants resorted to more suitable ways of determining quantities of food eaten. Similarly, they knew that according to MyFitnessPal, if they wanted to lose weight they need to stick to the daily calorie limit, but sometimes they would still digress from it to be able to enjoy social meals out. Thus, the use of MyFitnessPal shows dieters' negotiations between what was needed and what was convenient, rather than a blind following of the suggestions of the app.

Overall, exploration of the so far overlooked practical aspects of dieting provides us with a better understanding of the relationship between the practice of dieting (as well as technologies used) and those engaged in it. 


\subsection{References}

Bacon, H. (2015). Fat, syn, and disordered eating: The dangers and powers of excess. Fat Studies, 4(2), 92-111.

Bordo, S. (1993). Unbearable weight: Feminism, Western culture, and the body. University of California Press.

Comber, R., Hoohout, J., Van Halteren, A., Moynihan, P., \& Olivier, P. (2013). Food practices as situated action: Exploring and designing for everyday food practices with households. Changing Perspectives, 2457-2466.

Contois, E. J. H. (2013). Food and fashion: Exploring fat female identity in drop dead diva. Fat Studies, 2(2), 183-196.

Contois, E. J. H. (2015). Guilt-free and sinfully delicious: A contemporary theology of weight loss dieting. Fat Studies, 4(2), 112-126.

Coveney, J. (2006). Food, morals and meaning: The Pleasure and Anxiety of Eating (2nd ed.). New York: Routledge.

Crawford, R. (1984). A cultural account of "health": control, release, and the social body. In J. B. McKinlay (Ed.), Issues in the political economy of health care (pp. 60-103). New York: Tavistock Publications.

De la Rocha, O. L. (1985). The reorganization of arithmetic practice in the kitchen. Anthropology \& Education Quarterly, 16(3), 193-198.

De la Rocha, O. L. (1986). Problems of sense and problems of scale: An ethnographic study of arithmetic in everyday life. University of California, Irvine.

Espeland, W. N., \& Sauder, M. (2007). Rankings and reactivity: How public measures recreate social worlds. American Journal of Sociology, 113(1), 1-40.

Espeland, W. N., \& Stevens, M. L. (2008). A sociology of quantification. European Journal of Sociology, 49(3), 401-436.

Gard, M., \& Wright, J. (2005). The obesity epidemic. London: Routledge.

Gilman, S. L. (2010). Obesity: The biography. Oxford: Oxford University Press.

Groven, K., Råheim, M., \& Engelsrud, G. (2015). Changing bodies, changing habits: Women's experiences of interval training following gastric bypass surgery. Health Care for Women International, 36(3), 276-302.

Heyes, C. J. (2006). Foucault goes to weight watchers. Hypatia, 21(2), 126-149.

Kerr, S. J., Tan, O., \& Chua, J. C. (2014). Cooking personas: Goal-directed design requirements in the kitchen. International Journal of Human-Computer Studies, 72(2), 255-274.

Lupton, D. (1996). Food, the body and the self. London, Thousand Oaks: SAGE.

Macdiarmid, J., \& Blundell, J. (1998). Assessing dietary intake: Who, what and why of underreporting. Nutrition Research Reviews, 11(2), 231-253.

Martin, A., \& Lynch, M. (2009). Counting things and people: The practices and politics of counting. Social Problems, 56(2), 243-266.

Nafus, D., \& Sherman, J. (2014). This one does not go up to 11: The Quantified Self movement as an alternative big data practice. International Journal of Communications, 8, 17841794.

Niva, M. (2015). Online weight-loss services and a calculative practice of slimming. Health: An Interdisciplinary Journal for the Social Study of Health, Illness and Medicine. 21(4), 409-424

Oudshoorn, N. (2008). Diagnosis at a distance: The invisible work of patients and healthcare professionals in cardiac telemonitoring technology. Sociology of Health \& Illness, 30(2), 272-288.

Potter, J., Wetherell, M., \& Chitty, A. (1991). Quantification rhetoric - cancer on television. Discourse and Society, 2(3), 333-365.

Power, M. (2004). Counting, control and calculation: Reflections on measuring and 
management. Human Relations, 57(6), 765-783.

Rooksby, J., Rost, M., Morrison, A., \& Chalmers, M. C. (2014). Personal Tracking As Lived Informatics. In Proceedings of the SIGCHI Conference on Human Factors in Computing Systems (pp. 1163-1172). ACM Press.

Schwartz, H. (1986). Never satisfied: Social history of diets, fantasies and fat. New York, London: The Free Press.

Stinson, K. (2001). Women and dieting culture: Inside a commercial weight loss group. Rutgers University Press.

Throsby, K. (2008). Happy re-birthday: Weight loss surgery and the 'new me'. Body \& Society, $14(1), 117-133$. 